\section{Discussion}

As a pathologic entity this particular subtype may not constitute a distinct tumor from the other types of clear cell tumors, as suggested in the early 1980s. ${ }^{2,4}$ However, further clinicopathologic, immunohistochemical, and ultrastructural studies of subsequent case reports support CCC as a distinct subtype of large cell carcinoma with purely clear cell features or classified into squamous or adenomatous variants, depending on the type of cellular differentiation. ${ }^{3}$ In our case, no squamous or adenomatous differentiation was seen, and the tumor grew into and completely occluded the right main bronchus. This biologic behavior appears to be more benign than that seen in other types of non-small cell lung cancer.

\section{Conclusion}

CCC has rarely been reported in the literature, and cases of endobronchial compromise are even rarer. Histopathologically, this tumor must be differentiated from metastatic renal cell carcinoma, benign sugar tumor of the lung, predominant squamous mucoepidermoid carcinoma, and myoepithelial tumor. Immunohistochemical staining of tumor cells facilitates the differential diagnosis of these entities. Because of the low metastatic potential of these lesions and their rarity of recurrence, the role of chemotherapy for these lesions is dubious.

\section{References}

1. Iyoda A, Hiroshima K, Toyozaki T, Tsukamoto Y, Haga Y, Fujisawa T, et al. Clear cell adenocarcinoma with endobronchial polypoid growth. Pathol Int. 2000;50:979-83.

2. Gaffey MJ, Mills SE, Ritter JH. Clear cell tumors of the lower respiratory tract. Semin Diagn Pathol. 1997;14:222-32.

3. Hsu AA, Yeo CT, Ang HK, Ng HS, Ong YY. Clear cell carcinoma of the lung-a case report. Ann Acad Med Singapore. 1992;2:827-9.

4. Edwards C, Carlile A. Clear cell carcinoma of the lung. J Clin Pathol. 1985;38:880-5.

\title{
Successful enucleation of a giant cardiac hemangioendothelioma showing an unusual proliferation pattern
}

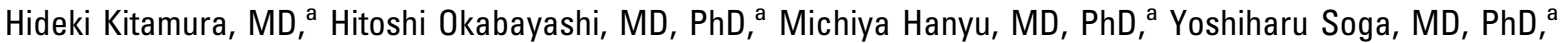 \\ Takuya Nomoto, MD, PhD, ${ }^{a}$ Hiroyuki Johno, MD, ${ }^{a}$ Jota Nakano, MD, ${ }^{a}$ Takehiko Matsuo, MD, ${ }^{\text {a }}$ Tadaaki Yokota, MD, PhD, \\ and Katsumi Inoue, MD, PhD, ${ }^{\mathrm{c}}$ Fukuoka, Japan
}

$\mathrm{P}$ rimary cardiac hemangioendothelioma is extremely uncommon, and just a few cases treated with surgical intervention are reported in the English literature. ${ }^{1-3}$ We report a case involving the peculiar appearance of a huge hemangioendothelioma that arose from the right ventricle and was successfully enucleated.

\section{Clinical Summary}

A previously healthy 36-year-old woman presented at our cardiac clinic with a 4-month history of cough and increasing edema in both legs. Cardiac examination revealed a Levine grade 2/6 systolic murmur and a sinus rhythm of 76 beats/min. Blood examination was unremarkable, including tumor markers, except for slight anemia (hemoglobin of $9.2 \mathrm{~g} / \mathrm{dL}$ ).

\footnotetext{
From the Departments of Cardiovascular Surgery, ${ }^{\mathrm{a}}$ Pathology, ${ }^{\mathrm{b}}$ and Laboratory Medicine, ${ }^{\mathrm{c}}$ Kokura Memorial Hospital, Fukuoka, Japan.

Received for publication April 6, 2005; accepted for publication May 3, 2005.

Address for reprints: Hideki Kitamura, MD, Department of Cardiovascular Surgery, Kokura Memorial Hospital, Kifunemati1-1, Kitakyusyu City, Fukuoka, 802-8555, Japan (E-mail: k-hideki@ @sc4.so-net.ne.jp).

J Thorac Cardiovasc Surg 2005;130:1199-201

$0022-5223 / \$ 30.00$

Copyright $\odot 2005$ by The American Association for Thoracic Surgery

doi:10.1016/j.jtcvs.2005.05.018
}

Chest radiography revealed cardiomegaly. On transthoracic echocardiography, it appeared as if the right ventricle was filled by a huge mass encircled with calcification and moderate tricuspid regurgitation. Computed tomography and magnetic resonance imaging of her chest revealed pericardial effusion and a mass lesion along the inferior border of the right ventricle, with calcification of its verge (Figure 1, A). The inner space of the mass matched to a hematoma on both images. Coronary angiography from the right coronary artery (RCA) revealed that the distal RCA was extended and occluded (Figure 1, B). Coronary angiography from the left coronary artery demonstrated late filling of the occluded distal RCA by reversed flow from the left coronary artery.

We diagnosed a cardiac tumor and operated on April 30, 2002. Through a median sternotomy, the pericardium was opened. The heart was surrounded by fibrin tissue, and there was a giant cardiac tumor that pushed up the whole heart in a cephalad manner.

Cardiopulmonary bypass was established with ascending aortic, superior vena caval, and right femoral venous cannulation. After cardiac standstill, the right atrium was opened. The right atrial intima and the tricuspid valve appeared intact. The right ventricular wall, including the RCA, was thin and extended by the cardiac tumor (Figure 1,C). We then cut the right ventricular wall and removed the tumor, which could be enucleated from the right ventricular mural wall without connection to the intraventricular cavity, except for small pin holes. We repaired these small pin holes and the right ventricular wall after trimming.

Histopathologic examination showed the excised tumor was an oval monolocular cyst of $12 \times 11 \mathrm{~cm}$ in diameter and clearly encapsulated by fibrous connective tissue. There was no extracapsular 

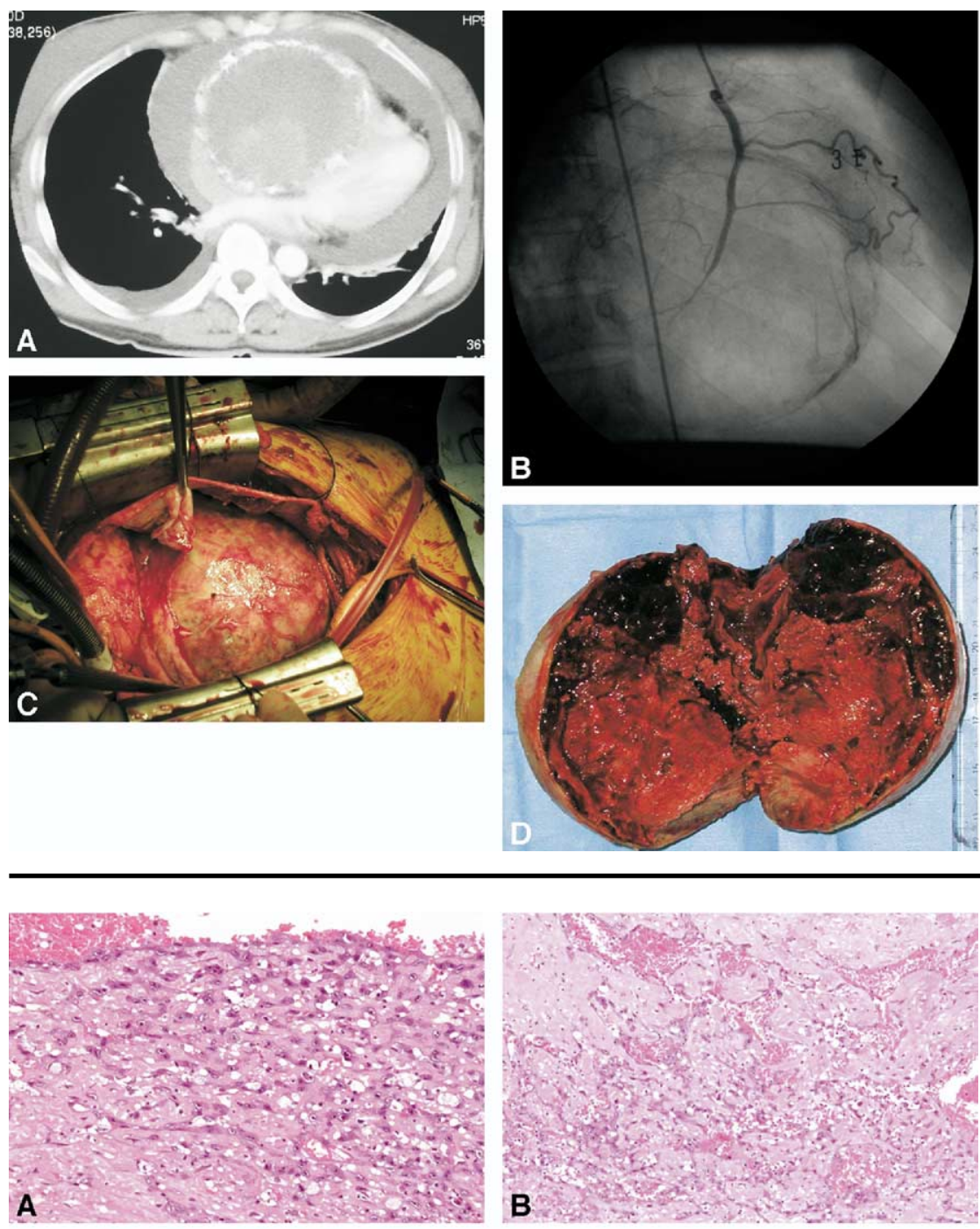

Figure 2. A, Atypical cells line the inner layer of the tumor wall. $B$, Formation of delicate vascular channels. C, Mitosis and oval vesicular nucleus or distorted nucleus, large clear nucleolus, and acidophil vacuole. D, Positive staining of CD34 and factor VIII-related antigen.

Figure 1. A, Preoperative computed tomography reveals pericardial effusion and a mass lesion along the inferior border of the right ventricle, with calcification of its verge. $B$, Coronary angiography from the right coronary artery reveals that the distal right coronary artery is extended and occluded. C, The right ventricular wall, including the right coronary artery, is thin and extended by cardiac tumor. D, The inner space of the tumor is filled by hematoma and fibrin.
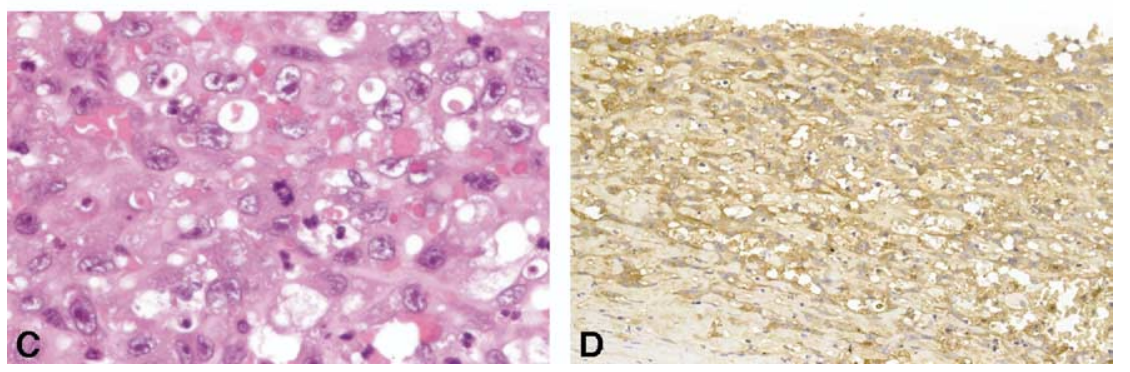

invasion pathologically. The inner space of the tumor was filled by hematoma and fibrin (Figure 1,D). The wall of the tumor was about $4 \mathrm{~mm}$ thick and consisted of fibrous connective tissue with hyaline degeneration and calcification. Atypical cells lined the inner layer of the tumor wall (Figure 2, A). Within the fibrous stroma, there were spindle and polygonal cells that formed a mesh or cordlike structure, and some cells appeared canalized in a formation of delicate vascular channels (Figure 2, B). Furthermore, some of these cells showed mitosis and possessed oval vesicular or distorted nuclei, large clear nucleoli, and acidophil vacuoles (Figure 2,C).
Immunohistochemical analysis showed negative staining for keratin and calretinin; however, positive staining of CD34 and factor VIII-related antigen (Figure 2,D) were clearly revealed. Some showed as heteromorphous, and the Ki-67 labeling index was approximately $25 \%$. Histologic diagnosis was hemangioendothelioma with an unusual proliferation pattern.

The postoperative course was uneventful, and the patient was discharged on the 18th postoperative day. Thereafter, the patient was followed up for about 3 years, with no sign of recurrence. 


\section{Discussion}

Hemangioendothelioma is a rare cardiac tumor, and just a few cases treated with surgical intervention are reported in the English literature. ${ }^{1-3}$ The tumor in the case we report here was huge and clearly encapsulated by calcification and fibrous connective tissue, which is why we could enucleate the tumor without difficulty.

Hemangioendothelioma is classified as an intermediate malignancy that sometimes metastasizes and recurs. ${ }^{4,5}$ This might indicate that we should have undertaken additional therapy, but Allaire and colleagues ${ }^{4}$ have reported that irradiation therapy or chemotherapy resulted in only palliation, whereas Hongquan and associates $^{1}$ revealed the prognosis of the hemangioendothelioma was relatively good once it was completely resected. In the present case, the tumor was successfully enucleated, and therefore we decided not to undertake additional therapy. The patient was then followed for about 3 years, with no sign of recurrence or metastasis.
Although it appears to have been clinically benign, this is an unprecedented giant tumor that showed an unusually proliferative pattern, and therefore further close follow-up is inevitable.

\section{References}

1. Hongquan Y, Hua R, Quancai C, Qi M, Xiaocheng L, Letian X. Cardiac hemangioendothelioma. J Cardiovasc Surg. 1998;39:655-8.

2. Gasparovic H, Anic D, Saric D, Gasparovic V, Djuric Z, Jelic I. Surgical excision of a hemangioendothelioma of the left ventricle. Ann Thorac Surg. 2002;74:914-6.

3. Ichikawa H, Kaneko T, Obayashi T, et al. Surgical treatment of malignant hemangioendothelioma originated from the right atrium. Kyobu Geka. 1997;50:67-70.

4. Allaire FJ, Grimm CA, Taylor LM, et al. Primary Hemangioendothelioma of the heart. Report of a case treated with irradiation and cyclophosphamide. Rocky Mt Med J. 1964;61:34-7.

5. Marchiano D, Fisher F, Hofstetter S. Epithelioid hemangioendothelioma of the heart with distant metastases. J Cardiovasc Surg. 1993;34:529-33.

\title{
Lymphangiomatous hamartoma: Cause or bystander of the isolated chylopericardium?
}

\author{
Charalambos Zisis, MD, $\mathrm{PhD},{ }^{a}$ Dimitra Rontogianni, $\mathrm{MD}, \mathrm{PhD},{ }^{\mathrm{b}}$ Eliana Charalambous, $\mathrm{MD}^{\mathrm{c}}$ and \\ Ion Bellenis, $\mathrm{MD}, \mathrm{PhD}^{\text {a }}$ Athens and Crete, Greece
}

$\mathrm{I}$ solated chylopericardium is an extremely rare pathologic entity, and about its cause there is a series of reasons sporadically reported in the literature. Lymphangiomatous hamartoma, a benign tumor of lymphangiomatous origin sparsely located exclusively to the mediastinum, has been considered one of the causes of the chylopericardium.

\section{Clinical Summary}

A 25-year-old male smoker of 7 pack-years was referred to our department from a district hospital for rapidly recurrent pericardial effusion (Figure 1) diagnosed 15 days before and showing no response to medication. During the 2 previous days, this progressively increasing effusion had caused clinical and echocardiographic features of pericardial tamponade and had been submitted twice to pericardiocentesis, with removal of $2.5 \mathrm{~L}$ and $800 \mathrm{~mL}$ of milky fluid, respectively. The laboratory results

\footnotetext{
From the Departments of Thoracic Surgery ${ }^{\mathrm{a}}$ and Pathology, ${ }^{\mathrm{b}}$ Evangelismos General Hospital, Athens, Greece, and the Intensive Care and Coronary Care Unit, "Venizelio" Hospital, Iraklion, Crete, Greece.

Received for publication April 29, 2005; accepted for publication May 20, 2005 .

Address for reprints: Charalambos Zisis, MD, PhD, 17A, Patriarchou Grigoriou str, 16674 Glyfada, Greece (E-mail: chzisis@otenet.gr).

J Thorac Cardiovasc Surg 2005;130:1201-2

$0022-5223 / \$ 30.00$

Copyright (C) 2005 by The American Association for Thoracic Surgery doi:10.1016/j.jtcvs.2005.05.025
}

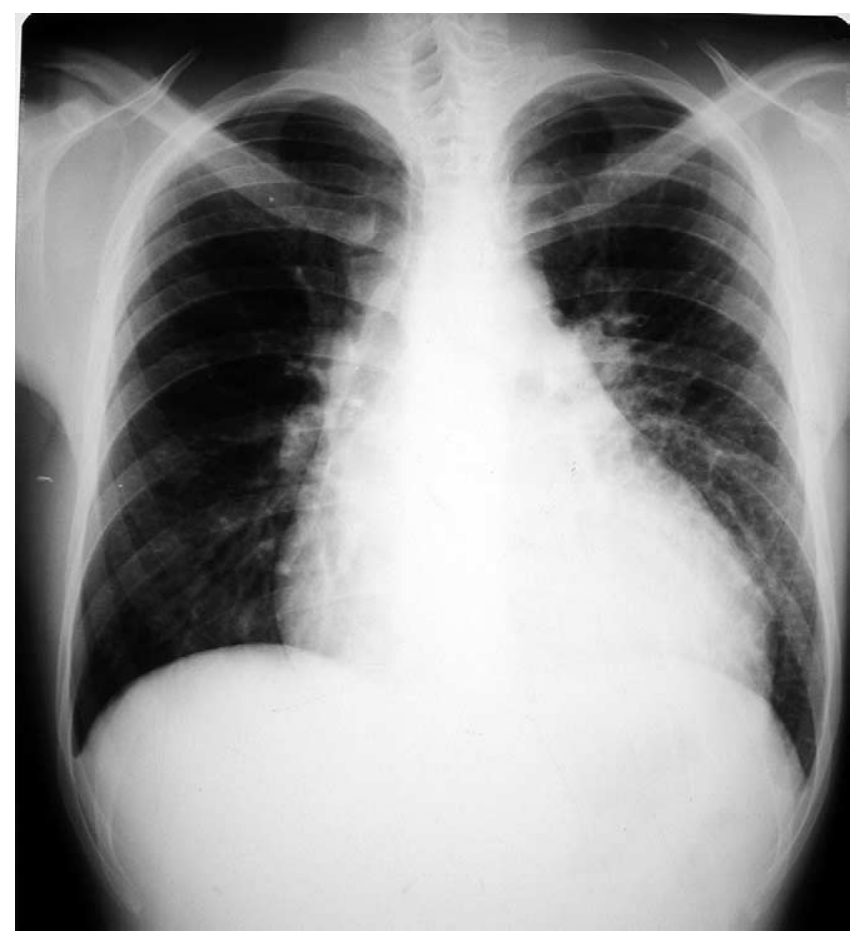

Figure 1. Preoperative chest $x$-ray film demonstrating enlargement of the cardiac silhouette contour caused by tamponade. 